\title{
ADAPTASI DAN TOLERANSI PENGUNGSI MAMUYA DI TOBELO HALMAHERA UTARA
}

\author{
Oleh
}

\author{
Berni Katudju, Maryam Lamadirisi, Rasyid Umaternate \& \\ Ferdinand Kerebungu \\ Universitas Negeri Manado \\ Correspondence Email: bernikatudju@yahoo.com
}

\begin{abstract}
Abstrak
Penelitian bertujuan untuk mengetahui faktor penyebab pengungsi Mamuya lebih memilih tetap tinggal di Desa Wari dibandingkan dengan kembali ke desa asalnya di Mamuya. Metode penelitian yang digunakan adalah metode kualitatif, dengan teknik pengumpulan data dilakukan dengan observasi dan wawancara. Teknik analisis data dilakukan dengan menggunakan teknik analisis data interaktif model Miles \& Huberman. Hasil penelitian menunjukkan bahwa: 1) rata-rata pengungsi Mamuya yang mengungsi di Desa Wari, sebagian besar beragama Kristen, ada juga sekitar 5 keluarga Protestan dengan jumlah keseluruhan tiga ratus penduduk. Persamaan agama dengan penduduk desa Wari menjadi salah satu pertimbangan khusus bagi para pengungsi untuk tetap tinggal; 2) pengungsi Mamuya merasa senang, dan menikmati hidup di Desa Wari, karena kedua desa masih memiliki ikatan keluarga.
\end{abstract}

Kata kunci: adaptasi, pengungsi mamuya, konflik horisontal

\begin{abstract}
The purpose of this research is to investigate factor of Mamuya refugees lived in the village of Wari rather than return to his native. The research methods used is qualitative methods. Techniques of data collection was observation and the interview to obtain data. The data analyze used in this research was data analyze interctive Miles \& Huberman. The research results showed as following: (1) the average refugee Mamuya in the villages of Wari is Christianity there was also about five percents of Protestant families of 300 inhabitants. Religious similarities between Wari and Mamuya as Christian are consideration for the Mamuya refugees to stay in Wari; (2) refugees Mamuya happiness and enjoy in Wari, because both of inhabitant have same ancestor in genealogical line.
\end{abstract}

Keywords: adaptation, mamuya refugees, horizontal conflict 


\section{Pendahuluan}

Konflik horizontal yang terjadi di Desa Mamuya Kecamatan Galela Kabupaten Halmahera Utara, pada awal bulan Januari pada tahun 2014 membuat situasi dan kondisi desa Mamuya mengalami kekacauan dan ketidakpastian. Masyarakat Mamuya khususnya yang beragama Kristen terbagi menjadi dua kelompok; kelompok yang satu mengatasnamakan Gereja Masehi Injil di Halmahera (GMIH), sedangkan kelompok yang satunya lagi mengatasnamakan Sidang Sinode Istimewa (SSI). Konflikkonflik demikian ternyata banyak terjadi di berbagai wilayah di Indonesia khususnya pada masa Reformasi. Latar belakang konflik di Tabole merupakan masalah klasik yang bersumber pada kurangnya toleransi dan kuatnya prejudice dalam masyarakat.

Keberadaan masyarakat yang mengatasnamakan Sidang Sinode Istimewa rupanya tidak diakui oleh jemaat Gereja Masehi Injil di Halmahera yang berakibat terjadinya konflik sosial dan kekerasan. Konflik terjadi antara kelompok masyarakat jemaat Gereja Masehi Injil di Halmahera melakukan aksi penyerangan kepada masyarakat jemaat Sidang Sinode Istimewa disertai dengan perusakan rumah, pembakaran bahan material bangunan gedung Gereja dan lain sebagainya. Tindakan yang dilakukan oleh sebagian besar masyarakat Mamuya kepada jemaat Sidang Sinode Istimewa tidak pernah dibalas namun masyarakat lebih memilih diam, dan mengamankan diri bersama keluarga masing-masing ke tempat yang lebih aman.

Melihat situasi dan kondisi desa Mamuya mulai tidak kondusif sehingga masyarakat memutuskan pergi untuk meninggalkan desa Mamuya pada tanggal 24 Ferbuari tahun 2014, kurang lebih 50 kepala keluarga dan 312 jiwa pergi mengungsi menyelamatkan diri ke Tobelo. Pengungsian ini merupakan awal dari kehidupan baru penduduk Mamuya karena pada perkembangannya mereka menetap di desa Wari. Kehidupan 
Desa Wari yang aman, damai, dan bersahabat merupakan salah satu faktor pendorong pengungsian.

Dalam masyarakat multikultur seperti bangsa Indonesia, toleransi, menghargai perbedaan, dan prasangka meru-pakan aspek penting untuk ditumbuh-kembangkan dalam masyarakat. Nilai-nilai tersebut merupakan pilar terpenting yang harus ada dalam rangka membangun masyarakat madani (civil society) yang demokratis dan berkeadilan. Dalam konteks tersebut Gueta (2013: 168) menegaskan pentingnya toleransi sebagai berikut:

Tolerance implies willingness to tolerate a position, idea or behavior, which are expressed by a person but considered wrong by his fellow. Nevertheless, the other acknowledges its existence, respecting the right and freedom of the other person to express them and to conduct his life according to those ideas, and beliefs.

Agama sebagai way of life bagi pengikutnya seharusnya dapat menjadi pendorong bagi umat manusia untuk selalu menegakkan perdamaian dan meningkatkan kesejahteraan bagi seluruh umat di bumi ini. Namun, realitanya adalah agama justru menjadi salah satu penyebab utama terjadinya konflik, kekerasanan dan kehancuran umat manusia (Sudrajat, 2014: 3). Dari berbagai konflik komunal ditemukan fakta bahwa perbedaan keyakinan, baik seagama maupun beda agama hanyalah sebagai faktor sekunder, sementara faktor primernya adalah masalah politik, sosial, maupun ekonomi. Fakta di lapangan menunjukkan, para elite sangat cerdas membungkus pesan politik yang bermakna simbolsimbol keagamaan demi mencapai kursi kekuasaan.

It is rooted in the prejudice, stereotype and attitude of the member of the ethnic and religious community toward one another that pertainesed to cultural identity that are relatively permanent owned by a group (Panggabean, 2004: 27).

Oleh karena itu, diperlukan upaya preventif agar masalah pertentangan agama tidak akan terulang lagi di masa yang akan dating, 
misalnya dengan mengintensifkan forum dialog antar umat beragama dan aliran kepercayaan (dialog antar iman), membangun pemahaman keagamaan yang lebih pluralis dan inklusif, serta memberikan pendidikan tentang pluralisme dan toleransi beragama melalui berbagai saluran pendidikan. Gueta (2013: 170) menyatakan bahwa dalam upaya menjaga dan menjamin perdamaian seharusnya menjadi konsensus yang berimplikasi pada tingkah laku yang produktif dan konstuktif bagi upaya perdamaian.

All efforts to establish and maintain peace are dependent on people's acknowledgement of human dignity which obliges educators to awaken respect for each individual in his or her inalienable personality regard-less age, gender, ethnicity, nationality, social status, educational standard and religion. Consequently, any violation of his or her personal intactness is in fundamental contradiction to the basic human values.

Faktanya masih banyak terjadi konflik yang mengatasnamakan perbedaan agama dan keyakinan di berbagai wilayah di Indonesia. Setiadi \& Kolip (2013: 91) menyebutkan bahwa konflik merupakan proses sosial masing-masing pihak yang berinteraksi berusaha saling menghancurkan, menyingkirkan, mengalahkan karena berbagai alasan seperti rasa benci atau rasa permusuhan. Kesuma (2017: 190) menyebutkan bahwa konflik merupa-kan bagian dari dinamika sosial terjadi secara paradoks, dimana pada satu sisi konflik memang merupakan hal yang buruk dan dapat menimbulkan kerugian. Tetapi disisi lain konflik merupakan proses peleburan nilai, norma, adat, dan budaya masyarakat yang memperkokoh nilai-nilai kebhinekaan.

Adaptasi merupakan proses penyesuaian diri terhadap lingkungan sosial, nilai-nilai sosial, bahasa, budaya, dan norma sosial yang terdapat di tengah masyarakat. Hal ini pula yang dilakukan oleh seluruh pengungsi Mamuya, ketika baru datang di Desa Wari Kecamatan Tobelo. Pengungsi Mamuya memahami bahwa hal paling mendasari ketika berada di suatu 
daerah atau wilayah yang baru perlu dilakukan yaitu beradaptasi secara cepat dengan warga asli Wari agar supaya menciptakan pola interaksi sosial dengan baik. Adaptasi meruapakan suatu penyesuaian pribadi terhadap lingkungan, penyesuaian ini dapat berarti mengubah diri pribadi sesuai dengan keadaan lingkungan pribadi, juga dapat berarti mengubah lingkungan sesuai dengan keinginan pribadi (Gerungan, 1991: 55).

Sebelum konflik horizontal melanda Desa Mamuya Kecamatan Galela sehingga membuat keadaaan sebagian masyarakat Mamuya mengungsi ke Desa Wari Kecamatan Tobelo Kabupaten Halmahera Utara. Relasi atau hubungan antara pengungsi Mamuya dengan masyarakat desa Wari, sudah sejak lama terbangun ada melalui seperti; aparatur sipil negara (ASN), keluarga, teman dan lain sebagainya. Berdasarkan hal tersebut maka proses adaptasi yang dilakukan oleh para para pengungsi Mamuya dalam proses beradaptasi dengan warga masyarakat Wari ternetralisir, meskipun secara umum para pengungsi Mamuya belum saling kenal satu dengan yang lain.

Awal kedatangan pengungsi Mamuya di Desa Wari Kecamatan Tobelo Kabupaten Halmahera Utara terjadi pada tahun 2014. Respon dari masyarakat warga Desa Wari menerima dengan baik pengungsi Mamuya untuk tinggal di desa meskipun pada saat itu pengungsi Mamuya adalah anggota Gereja Sidang Sinode Istimewa (SSI), namum masyarakat asli Wari dan warga sekitarnya tidak pernah mempermasalahkan mengenai hal itu. Di satu sisi bahwa masyarakat di Desa Wari mayoritas adalah anggota Gereja Masehi Injil di Halmahera (GMIH), namun perbedaan tersebut tidak menimbulkan gesekan atau konflik sosial di antara kedua kelompok masyarakat sehingga dapat menjalani kehidupan saling berdampingan satu dengan yang lain. Hal tersebut menjadi salah satu indikator bahwa masyarakat Desa Wari menghargai dan mengakui keberadaan pengungsi 
Mamuya sebagai kelompok yang berhak untuk memiliki keyakinan yang berbeda.

Masyarakat Desa Wari telah berpikir lebih maju, bertindak dan mampu menjunjung tinggi nilai-nilai dari keanekaragaman sehingga mampu mengimplementasikan dalam kehidupan sehari-hari. Keberadaan adanya pengungsi Mamuya di Desa Wari Kecamatan Tobelo, bukan menjadi masalah namun memberikan warna kehidupan yang baru dalam kemajuan desa yang dicita-citakan bersama. para pengungsi Mamuya merasa nyaman dengan lingkungan dan sikap dari warga masyarakat Desa Wari yang lebih terbuka dan menerima hal-hal yang baru sehingga pengungsi Mamuya memutuskan untuk menentap di Desa Wari dan tidak memiliki keinginan untuk kembali ke Desa Mamuya. Hal tersebut menjadi menarik diteliti proses adaptasi para pengungsi sehingga dapat diterima di Desa Wari.

\section{Metode Penelitian}

Pendekatan penelitian yang digunakan dalam penelitian ini adalah metode kualitatif. Sumber data penelitian ditentukan adalah para aparatur sipil negara, tokoh masyarakat, tokoh adat, generasi muda dan para pengungsi Mamuya yang ada di Desa Wari. Alasan ditetapkan sebagai informan kunci karena pihak-pihak tersebut merupakan orang-orang yang tahu banyak tentang hal-hal serta persoalan-persoalan yang diteliti. Proses pengumpulan data dilakukan melalui observasi, wawancara semi terstruktur. Menggunakan teknik analisis data interaktif menurut Miles dan Huberman (Sugiyono 2013: 337) meliputi: collecting data, display data, data reduction and conclusion. Peneliti melakukan crosscheck antara informasi dari satu respondent dengan respondent lainnya untuk memperoleh simpulan. Crosscheck juga dilakukan dengan cara membandingkan informasi wawancara dengan hasil pengamatan. 


\section{Hasil dan Pembahasan}

Salah satu kegiatan pengungsi dalam menjalin persahabatan dan kedekatan sosial dengan cara ikut berpartisipasi dalam kerja bakti dan kerja sosial (gotong royong). Hal tersebut merupakan salah satu cara yang sering kali dilakukan pengungsi Mamuya untuk mendekatkan diri dengan masyarakat. Pemerintah Desa Wari Kecamatan Tobelo dan masyarakat Desa Wari sering kali mengadakan kerja bakti secara bersama-sama dengan seluruh lapisan masyarakat melibatkan pengungsi Mamuya agar dapat mengambil bagian dalam perkerjaan yang akan dilaksanakan. Respon pengungsi Mamuya senang hati berbondong-bondong datang dan melibatkan diri dalam kegiatan yang dilaksanakan. Tujuan diadakan kegiatan tersebut yaitu yang diinginkan oleh semua pihak dengan memperkuat dan mempererat tali persaudaraan diantara kedua kelompok masyarakat agar saling mengenal satu dengan yang lain. Sehingga terciptanya hubungan kekeluargaan sambil melestarikan budaya warisan dari nenek moyang.

Saling bersilaturahmi dalam perayaan hari-hari besar umat Kristiani seperti natal dan tahun baru. Pengungsi Mamuya dan masyarakat Desa Wari, berupaya saling mengujungi dari rumah ke rumah untuk bersilaturahmi secara individu atau kelompok dalam membangunan hubungan kekeluargaan yang sementara berjalani agar tetap terjaga dengan baik. Tak jarang dalam momentum tersebut dimanfaatkan oleh kelompok masyarakat untuk melakukan kegiatan pencarian dana pembangunan gereja baru.

Terlibat aktif dalam acara duka. Apabila masyarakat terdapat yang meninggal dunia dialami oleh masyarakat Desa Wari atau pengungsi Mamuya, kedua masyarakat akan berbaur sama-sama melayat ke rumah duka. Kegiatan melayat untuk menghibur dan memanjatkan doa keluarga yang mengalami duka. Setiap warga yang melayat ke rumah duka pasti 
akan membawa bantuan seperti uang, gula, tepung terigu dan lain sebagainya. Proses pembagian kerja jelas antara kaum perempuan yaitu mengambil bagian di dapur untuk memasak sedangkan kaum pria membantu membuat tenda dan mengali liang kuburan.

Saling tolong menolong ketika berada dalam acara perkawinan atau pelaksaan lamaran yang dilakasanakan oleh masyarakat Desa Wari. Terkadang masyarakat Desa Wari dan warga sekitar meminta bantuan kepada tokoh adat dari pengungsi Mamuya untuk bertindakan sebagai ketua juru bicara dalam pelaksanaan lamaran anak perempun atau anak laki-laki. Alasan tersebut dilatarbelakangi bahwa terdapat penilaian masyarakat Desa Wari terhadap beberapa tokoh adat dari pengungsi Mamuya berpengalaman dalam pelaksaan lamaran sehingga mampu mengambil kebijakan yang tepat sehingga menguntungkan kedua belah pihak.

Senada dengan hal itu menurut Soeharto Heerdjan (dalam Winata, (2014: 13) "penyesuaian diri adalah usaha atau perilaku yang tujuan mengatasi kesulitan dan hambatan". Berdasarkan penjelasan teori yang dikemukakan oleh Soeharto Heerdjan, sesungguhnya bahwa dalam proses penyesuaian diri adalah usaha manusia melakukan cara agar dapat mencapai tujuan yang diinginkan sehingga dapat keluar dari kesulitan yang dihadapi baik secara individu atau kelompok masyarakat ketika berada dalam satu wilayah. Hal tersebut pula yang dilakukan oleh seluruh pengungsi Mamuya ketika berada di Desa Wari. Masyarakat pengungis Mamuya memahami secara benar bahwa kesulitan yang dialami dalam beradaptasi dengan masyarakat Desa Wari. Oleh karena itu pengungsi Mamuya melakukan trobosan agar dapat keluar dari permasalahan yang dihadapi dalam bermasyarakat. Maka dilakukannya seperti, ikut berpartisipasi dalam kegiatan kerja bakti sosial (gotong royong), terlibat aktif dalam acara kedukaan yang dialami baik masyarakat Desa Wari atau 
pengungsi Mamuya, dan saling bersilaturahmi dalam perayaaan hari-hari besar seperti natal dan tahun dan lain sebagainya.

Berdasarkan uraian tentang upaya-upaya yang dilakukan oleh pengungsi Mamuya dalam upaya beradaptasi dengan masyarakat Desa Wari, ternyata membuahkan hasil yang baik. Penerimaan pengungsi Mamuya oleh masyarakat Desa Wari secara perlahan masing-masing kelompok masyarakat sudah dapat menerima. Sehingga baik pengungsi Mamuya dan masyarakat Desa Wari telah dapat berbaur menjadi satu dalam kehidupan bermasyarakat. Hal tersebut dalam observasi kegiatan social, ekonomi dan keagamaan dalam kehidupan secara hari-hari tanpa membeda-bedakan satu dengan lain.

Cara yang dilakukan oleh pengungsi Mamuya ketika berada di Desa Wari Kecamatan Tobelo adalah melakukan interaksi sosial kepada seluruh masyarakat yang ada di Desa Wari, baik secara individu atau kelompok agar kedua masyarakat saling kenal. Secara perlahan-lahan interaksi sosial yang dilakukan para pengungsi Mamuya kepada masyarakat Desa Wari berjalan dengan baik karena terjadi hubungan timbal balik diantara masyarakat sehingga pengungsi mampu melakukan penyesuaian diri dalam masyarakat Desa Wari bahkan dengan lingkungan sosialnya. Contoh bentuk kerja sama yang dilakukan oleh pengungsi Mamuya bersama masyarakat Desa Wari adalah pada saat pengecoran tiang beton gereja Imanuel Mamuya, kedua kelompok masyarakat berkerja sama-sama dalam menyelesaikan perkerjaan agar cepat selesai. Sejalan dengan hal itu, menurut Soekanto (2009: 54) interaksi sosial merupakan kunci dari semua kehidupan sosial karena tanpa interaksi sosial, tak akan mungkin ada kehidupan bersama. Suatu masyarakat untuk dapat beradaptasi pastinya akan didahului oleh proses intraksi, sebab tanpa interaksi adaptasi tidak akan mungkin tercapai. 
Pengungsi Mamuya ketika berada di Desa Wari Kecamatan Tobelo Kabupaten Halmahera Utara, hal pertama dilakukan adalah membangun interaksi sosial dengan masyarakat Desa Wari, baik secara individu atau kelompok agar supaya terjalinnya hubungan timbal balik antara individu dengan kelompok masyarakat. Hal ini dilakukan karena membangun interaksi sosial merupakan hal paling mendasari yang tidak bisa di tawar dalam proses adaptasi sosial para pengungsi Mamuya dengan masyarakat Desa Wati. Kegiatan tersebut berjalan lancar sehingga mendapatkan titik temu antara kedua kelompok dapat mengakui dan menghargai setiap perbedaan. Sepangjang berjalannya waktu para pengungsi Mamuya mampu beradaptasi dengan masyarakat Wari, karena interaksi sosial dan komunikasi yang dilakukan oleh para pengungsi boleh diterima masyarakat Desa Wari. Terdapat beberapa faktor para pengungsi Mamuya mampu beradaptasi di Desa Wari antara lain sebagai berikut:

\section{1) Faktor Agama.}

Berdasarkan data yang diperoleh di lapangan menunjukan bahwa rata-rata pengungsi yang menyelamatkan diri ke Desa Wari Kecamatan Tobelo, kurang lebih 50 kepala keluarga sekitar 300 jiwa semuanya pemeluk agama Kristen Protestan. Masyarakat di Desa Wari juga mayoritas memeluk beragama Kristen Protestan. Hal ini dapat dilihat dari bangunan gedung gereja di Desa Wari, berdiri kokoh terdapat lima gereja dan terdapat satu masjid.

Kesamaan agama Kristen antara pengungsi Mamuya dengan masyarakat Desa Wari, inilah yang dimanfaatkan secara baik oleh para pengungsi Mamuya dalam proses adaptasi sosial dengan masyarakat Desa Wari. Sehingga dengan mudah para pengungsi beradaptasi dan tidak mengalami kesulitan dalam menarik empati dari warga masyarakat desa Wari. Persamaan dalam keyakinan dapat merekatkan hubungan sosial 
antar kelompok masyarakat karena simbol primordialistik menjadi satu pengikat yang efektif dalam kelompok.

\section{2) Faktor Keluarga.}

Terdapat beberapa kepala keluarga dari pengungsi Mamuya dengan masyarakat Desa Wari masih mempunyai hubungan emosional. Masyarakat Mamuya jauh sebelumnya telah menikah dengan masyarakat Desa Wari seperti keluarga Pinoke, Gosango dan Dawile. Ketika konflik horizontal melanda di Desa Mamuya sehingga membuat sebagian masyarakat Mamuya mengungsi menyelamatkan diri ke Desa Wari. Hal pertama kali yang dilakukan oleh pengungsi Mamuya ialah mencari sanak saudara yang memiliki tempat tinggal di Desa Wari untuk berlindungan. Hubungan kekeluargaan dengan masyarakat Desa Wari inilah yang dimanfaatkan oleh pengungsi Mamuya dalam proses menyesuaikan diri. Hal tersebut memudahkan para pengungsi Mamuya melakukan sosialisasi dengan masyarakat Desa Wari. Hubungan masyarakat Desa Wari dengan pengungsi Mamuya memiliki relasi sebelumnya telah terbangun melalui hubungan keluarga, meskipun masih skala kecil. Meskipun dalam skala kecil akan tetapi membantu para pengungsi Mamuya dalam proses beradaptasi dengan tetangga barunya tersebut.

Menurut Winata (2014: 15) mengatakan terdapat beberapa faktor penghambat dan pendukung dalam proses adaptasi bagi pendatang:

1) Proses yang menghambat dalam beradaptasi sosial:

a) Perbedaan-perbedaan dalam keyakinan inti, nilai-nilai, dan normanorma situasional antara di tempat asal dan di tempat baru.

b) Hilangnya gambaran-gambaran budaya asal yang dipegang dan semua citra dan simbol yang familiar yang menandakan bahwa identitas yang dulu familiar dari para pendatang baru telah hilang. 
c) Rasa ketidakmampuan para pendatang dalam merespon peraturan baru secara tepat dan efektif.

2) Proses yang mendukung dalam adaptasi sosial:

a) Rasa tentram dan meningkatnya harga diri.

b) Fleksibilitas dan terbukaan kognitif.

c) Kompetisi dalam berinteraksi sosial dan meningkatnya kepercayaan diri dan merasa percaya orang lain.

Berdasarkan pendapat di atas dapat disimpulkan bahwa jika perbedaan-perbedaan keyakinan inti menjadi faktor penghambat ketika dalam beradaptasi. Berbeda halnya dengan pengungsi Mamuya ketika dalam beradaptasi dengan masyarakat Desa Wari. Faktor agama dan faktor keluarga dijadikan modal utama bagi pengungsi Mamuya ketika beradaptasi dengan seluruh lapisan masyarakat yang berada di Desa Wari. Kedua faktor tersebut membantu untuk keluar dari kesulitan yang dihadapi ketika berada di lapangan. Pengungsi Mamuya menjadikan agama dan keluarga sebagai alat untuk bersosialisasi dengan masyarakat agar mampu beradaptasi. Berjalan waktu proses adaptasi pengungsi Mamuya dengan masyarakat berjalan dengan baik karena masing-masing kelompok telah dapat menerima dan mengakui keberadaan sehingga kedua masyarakat berbaur menjadi satu dalam kehidupan sehari-hari.

Keberhasilan pengungsi Mamuya yang mampu beradaptasi dengan masyarakat Desa Wari, membuat sebagian besar pengungsi merasa nyaman, senang, tentram dan meningkatnya harga diri. Hal tersebut disebabkan oleh kondisi lingkungan sosial yang aman serta masyarakat ramah dan sangat menghargai segala perbedaan yang terdapat di tengah masyarakat Desa Wari. Hal ini dapat dilihat dari interaksi sosial yang terjalin diantara kedua masyarakat dalam kehidupan sehari-hari. Sehingga pengungsi Mamuya sudah memantapkan hati untuk tinggal dan merubah status kependudukan pada KTP menjadi warga masyarakat Desa 
Wari Kecamatan Tobelo Kabupaten Halmahera Utara. Selain memerbarui data kelurarga, tempat tinggal dan tempat ibadah dibangun secara parmanen karena pengungsi Mamuya sudah tidak terdapat niat untuk kembali ke desa asalnya. Pengungsi Mamuya yang telah menjadi warga masyarakat Desa Wari mencoba membangun dan merajut kembali hubungan kekeluargaan yang sempat hancur akibat dari konflik sosial yang pernah terjadi.

Kehidupan masyarakat Desa Wari, sebelum adanya pengungsi Mamuya tidak jauh berbeda dengan masyarakat pedesaan pada umumnya. Masyarakat menjalankan aktifitas sehari-hari dengan bermacam-macam profesi yang dilakukan oleh masyarakat Desa Wari antara lain; ASN, TNI, Polri, nelayan, buruh bagasi, kuli bangunan, peternak, buruh tani, karyawan swasta dan lain sabagainya. Desa Wari memiliki keuggulan yang tidak dimiliki oleh desa-desa lain, karena letak Desa Wari berdekatan dengan dua kampus swasta sehingga ada sebagaian masyarakat yang mempunyai usaha rumah kos dan usaha rumah makan karena melihat peluang bisnis yang sangat menjanjikan. Desa Wari sangat strategis jika dilihat letak geografis sebab berdekatan dengan Kecamatan Tobelo dan ibu kota Kabupaten Halmahera Utara, sehingga mobilitas barang dan jasa yang sangat cepat. Tingkat keterjangkauan antara Kecamatan Toblelo dengan Ibu Kota Kabupaten Halmahera Utara tidaklah sulit sebab dapat menggunakan sepeda motor atau mobil dengan waktu tempuh 4-10 menit. Meskipun Desa Wari berdekatan dengan Kecamatan Tobelo dan Ibu Kota Kabupaten Halmahera Utara akan tetapi kebanyakan masyarakatnya Desa Wari berkerja sebagai petani di kebun.

Semenjak kedatanganan pengungsi Mamuya di Desa Wari, sektor pertanian khususnya ditanam tanaman bulanan atau sector pangan didominasi oleh pengungsi Mamuya yang pandai dalam memanfaatkan lahan PT Perkebunan Nusantara untuk bertani. Alasannya pengungsi 
Mamuya menanam tanaman bulanan adalah memenuhi kebutuhan hidup dan melihat peluang bisnis. Andai sebelumnya masyarakat Desa Wari hanya mengandalkan sektor pertanian tanaman tahunan seperti kelapa, pala dan cengkeh mencukupi kebutuhan hidup dan kurang memperhatikan lahan untuk memanfaatkan bercocok tanaman seperti singkong, pisang, sayur-sayuran, tomat, cabe, kacang-kacangan dan lain sebagainya. Masyarakat Desa Wari mulai mengadopsi cara memanfaatkan lahan untuk bercocok tanam seperti yang dilakukan oleh pengungsi Mamuya. Cara ini ambil oleh masyarakat Desa Wari selain memenuhi kebutuhan hidup namun juga melihat peluang bisnis yang sangat menguntungkan bagi masyarakat.

Adaptasi adalah suatu penyesuaian pribadi terhadap lingkungan, penyesuaian ini dapat berarti mengubah diri pribadi sesuai dengan keadaan lingkungan pribadi, juga dapat berarti mengubah lingkungan sesuai dengan keinginan pribadi (Gerungan, 1991:5 5). Masyarakat Desa Wari dan pengungsi Mamuya sama-sama melakukan penyesuaian diri terutama dalam sektor pertanian. Masyarakat Desa Wari mengadopsi cara bercocok tanam dengan tanaman bulanan seperti yang dilakukan oleh pengungsi Mamuya untuk memanfaatkan lahan untuk mengelolah menanam kebutuhan pangan. Pengungsi Mamuya juga beradaptasi cara mengelolah lahan pertanian untuk menanam pala, kelapa dan cengkeh. Sehingga proses adaptasi yang dilakukan oleh masyarakat Desa Wari dan pengungsi Mamuya melahirkan sesuatu proses yang baru dalam masyarakat.

Terbukanya akses jalan berperan dalam membawa dampak positif bagi masyarakat Desa Wari terlebih khusus bagi petani. Perbaikan akses jalan membantu bagi petani dalam pergi pulang ke kebun sehingga tidak mengalami kesulitan dalam melakukan aktivitas. Sehingga hasil pertanian bumi seperti kelapa, pala, cengkeh dan lain sebagainya dapat dipasarkan 
oleh pertani secara cepat. Daya dukung infrastruktur jalan yang memadai tidak jarang konsumen membeli secara langsung ke kebun untuk dapat melakukan aktivitas transaksi jual dan beli hasil pertanian. Fasilitas dan kemudahan di desa Wari menjadikan pengungsi semakin nyaman berada di desa tersebut. Mereka berharap dapat merajut kehidupan yang lebih baik dalam bidang ekonomi dan sosial budaya.

\section{Simpulan}

Pengungsi Mamuya menyelamatkan diri ke Desa Wari Kecamatan Tobelo Kabupaten, semuanya pemeluk agama Kristen Protestan sedangkan masyarakat Desa Wari mayoritas juga beragama Kristen Protestan. Hal tersebut dapat dilihat dari banyaknya bangunan gereja yang berdiri kokoh Desa Wari yaitu sebanyak lima gedung gereja. Faktor kesamaan agama menjadi salah satu modal atau keuntungan tersendiri bagi pengungsi Mamuya sehingga dengan mudah mampu beradaptasi dengan masyarakat Desa Wari. Berdasarkan kesamaan dalam hal agama antara masyarakat asal dan tujuan pengungsi, sehingga mempermudah pengungsi Mamuya dalam berinteraksi sosial dengan masyarakat Desa Wari

Hubungan kekeluargaan menjadi salah satu faktor yang menyebabkan pengungsi Mamuya mampu beradaptasi dengan masyarakat Desa Wari. Sebab sebelumnya para masyarakat Mamuya telah menikah dan berkeluarga di masyarakat Desa Wari seperti keluarga Pinoke, Gosango, Dawile, dan-lain sebagainya. Perkawinan diantara kedua masyarakat ini yang menjadi modal dasar bagi pengungsi Mamuya dalam beradaptasi dengan desa Wari. Alasan tersebut membantu dalam proses menyesuaikan diri sehingga pengungsi Mamuya tidak mengalami kesulitan yang berarti dalam berinteraksi dan berkomunikasi dengan masyarakat pada umumnya sehingga terjadilah adaptasi dan pembauran di desa Wari. 


\section{Daftar Pustaka}

Gerungan, (1991). Pshychologi Sosial (Suatu Ringkasan). Bandung : PT. Eresco.

Gueta, S., (2013). From peace education to culture of peace: context and issues., Studi sulla formazione, 1-2013,167-179.

Ismail, H. B. (2005). Adaptasi sosial mahasiswa asal Tidore di Kelurahan Titiwureng Selatan Kota Manado. Jurnal Holistik, 8, (15).

Kesuma, T. A. R. P. (2017). Pola integrasi dalam masyarakat majemuk. JIPSINDO, 4, (2).

Nurjihan, H., Nurdin, F., \& Muhamad, T. (2017) Adaptasi sosial masyarakat kawasan banjir di Desa Bojongloa Kecamatan Rancaekek, Jurnal Pemikiran dan Penelitian Sosiologi, 2, (1).

Panggabean, S. R. (2004). Approahes to ethnic conflict resolution. Dalam Triyono, L. (ed). The making of ethnic \& religious conflict in Southeast Asia. Yogyakarta: CSPS Book.

Setiadi, E \& Kolip, U. (2013). Pengantar sosiologi (pemahaman fakta dan gejala permasalahan sosial: teori, aplikasi, dan pemecahan-nya). Jakarta: Kencana.

Sudrajat, S. (2014). Pendidikan multikultural untuk meningkatkan kualitas pembelajaran IPS di sekolah dasar. JIPSINDO, 1, (1) 1-14.

Sugiyono, (2013). Metode penelitian kuantitatif, kualitatif, dan R\&D. Bandung: Alfabeta.

Soekanto, S. (2009). Sosiologi suatu pengantar. Yogyakarta: LKis

Winata, A. (2014). Adaptasi sosial mahasiswa rantau dalam mencapai prestasi akademik. Bengkulu: FISIP UB. 